\title{
Entrepreneurial Improvisation: Research Review, Integration Framework and Future Outlook
}

\author{
Xuejiao XU, Yaqi ZHAO, , and Jing ZHANG \\ School of Economics and Management, Beihua University, Jilin, China
}

\begin{abstract}
At present, the development context of entrepreneurial improvisation research is still unclear. This article reviews and sorts out the relevant literature on entrepreneurial improvisation from the individual and organizational levels: starting from the connotation, constituent elements and induction mechanism, classifies and sorts out the relevant research on entrepreneurial improvisation, and proposes an integrated framework and framework based on the summary of the frontier topics of entrepreneurial improvisation. The prospect of the future is expected to provide reference for the in-depth research and practice of entrepreneurial improvisation in the future.
\end{abstract}

Keywords: Entrepreneurial Improvisation, Improvisation Ability, Environmental Turbulence, Research Review

\section{Introduction}

Under the policy of "mass entrepreneurship and innovation", the whole people actively participate in the entrepreneurial boom. However, the sluggish success rate of entrepreneurship and the dynamic changes in the environment present provide great difficulties for entrepreneurs. How to make strategies that are most in line with the current and conducive to the future under the uncertain and unpredictable decision-making environment has become the key to the endurance of startups and a hot topic of academic discussion. Since Weick first introduced improvisation to the development of the management field, entrepreneurial improvisation has provided a new perspective for the survival and development of enterprises and is one of the research topics in the field of entrepreneurship.

Many literatures show that entrepreneurial improvisation can have a positive impact on the performance and sustainable development of enterprises. Impromptu greatly shortens the time gap between planning and execution, improves the effectiveness of resources at hand, and helps companies grasp the opportunity in a rapidly changing environment. In the process of business survival and growth, it is not an easy process to make appropriate plans. Startups need to consider improvisation, because it can change the strategic plan so that the company can respond immediately when opportunities arise (Arshad, Darwina, et al.,2018) [1]. Many scholars at home and abroad try to explain the formation mechanism of entrepreneurial improvisation from a certain theoretical perspective, but the research on the

* Corresponding author: zhaoyaqi9508@126.com 
in-depth analysis of the development context of entrepreneurial improvisation is relatively scarce. Since entrepreneurial improvisation is still in its growth stage, systematically combing existing relevant literature is of great significance for the further research of entrepreneurial improvisation in the future. Based on this, this article reviews and sorts out relevant literature on entrepreneurial improvisation from the individual and organizational levels, hoping to provide a reference for in-depth research and practice of entrepreneurial improvisation in the future.

\section{Research on the definition of entrepreneurship improvisation}

\subsection{Individual perspective}

Weick (1993) first introduced organizational improvisation into the management field, and he regarded improvisation as a process-immediately inventing new methods and strategies to replace the old order [2]. Later, scholars introduced resource patchwork in the study of improvisation. Guoxiang Ruan et al. (2015) believed that employee improvisation is a behavioral way in which startups rely on employee spontaneity and creativity and use available resources to respond to and solve many unexpected technical and management problems in a dynamic environment [3]. On this basis, Ying Wang and Taoyong Su (2019) introduced emotion to the level of individual improvisation in subsequent empirical research related to improvisation, enriching individual level research, and defined employee improvisation as the creative use of resources at hand to quickly respond to task goals and solve accidents on the spot. Problem behavior is the result of comprehensive investment in cognition, emotion, and resources [4].

\subsection{Organizational perspective}

Moorman and Miner (1998) summarized organizational improvisation as "the degree of aggregation of creation and execution in time" [5]. Emphasis on time cohesion, but in subsequent research, spontaneity and innovation have become the new focus of the concept of organizational improvisation. Vera and Crossan (2005) are based on the process orientation of improvisation, and they believe that improvisation is a creative and spontaneous process to achieve organizational goals in a new way [6]. In addition, because the limited resources will restrict the development of the organization, Cunha et al. (1999) defined organizational improvisation as the concept of action carried out by the organization or its members based on available material, cognitive, emotional and social resources [7]. Leybourne and Sadler (2006) emphasized the influence of the organizational environment, and believed that organizational improvisation is driven by time pressure, a mixture of intuition, creativity and the use of available resources [8]. In addition, Zhuxin Ye et al. (2018) emphasized the contextualization of entrepreneurial impromptu, believing that entrepreneurial impromptu is the behavior of entrepreneurial teams re-integrating the resources available at their counterparts and consciously integrating the creation and execution of new solutions [9]. 


\section{Research on the elements of entrepreneurship improvisation}

\subsection{Dimension Division}

Early research on improvisation mainly focused on spontaneity, and the research structure was relatively simple. After that, the dimension of entrepreneurial improvisation was gradually expanded. Croosan and Sorrenti (1997) proposed to take intuition and spontaneity as the two dimensions of improvisation, and began to consider the influence of intuition [10]. Miner et al. (2001) believes that organizational improvisation includes four dimensions: novelty, consciousness, time aggregation and resource concentration [11]. On the basis of Vera, Hmieleski and Corbett (2006) divided improvisation into creativity and utilization of resources at hand, execution ability under high pressure environment, spontaneity and persistence [12], Jiang Yun and Chen Jiang (2010) inherited Miner's resource concentration Thought, it is proposed that organizational improvisation consists of three dimensions: immediate response, intention to create and use of existing resources [13]. In subsequent research, Lin Ding and Guangming Cao (2014) and others defined organizational improvisation at the organizational level into four dimensions: immediate response, intention creation, instant collaboration and resource integration [14].

\subsection{Measurement method}

Hmleleski and Corbett (2008) et al. selected 12 of the above 27 items as a more comprehensive scale for measuring individual improvisation [15]. Massimo (2009) et al. modified the scale on the basis of the scale developed by Vera and Crossan (2005), using a seven-item scale to measure the degree of individual improvisation, which mainly expresses the two aspects of creativity and immediacy [16].Moorman and Miner (1998) used two methods to measure improvisation at the same level of analysis relative to planning: the time difference between plan and execution, and the degree of deviation from the previous plan [5], Subsequently, in his research on the improvisational behavior of new product development teams, the scale was used for the first time to measure improvisational behavior, which laid the foundation for the development of improvisational scales. Vera and Crossan (2005) developed a relatively complete organizational improvisation scale on the basis of the existing employee creation power scale, spontaneity measurement and improvisation measurement, with a total of 7 tests [6]. Lin Ding and GuangMing Cao (2014) developed an organization-level improvisation scale based on the research on the organizational improvisation ability of commercial banks, which specifically includes 4 dimensional variables and 19 measurement items [14].

\section{Research on the induction mechanism of entrepreneurship}

\subsection{Management related factors}

In previous studies, leadership style is one of the important influencing factors of improvisational behavior. For example, the essence of transformational leadership helps employees not be restricted by the organizational framework, and while supporting employees, it also makes them improvise in necessary situations (Haidong Li and Zhiyang Lin ,2013) [17]. Similarly, inclusive leadership uses a leadership style that respects the personality of employees, encourages employees to play positively and tolerate mistakes, enhances employee recognition and sense of belonging, and promotes employee improvisation. Entrepreneurial leadership creates an atmosphere of innovation for the 
organization, giving people self-confidence. Under the call of innovation, employees can have an improvisation that is inherently compatible with entrepreneurial leadership (Ying Wang and Taoyong Su ,2019) [4].

\subsection{Emotional social interaction related Factors}

Research has found that organizational emotions triggered by contextual changes can provide an information source for the organization's temporary performance, generate instant activities suitable for the current situation, and can be adjusted in real time based on emotional responses. Organizational impromptu behavior is affected by the relationship between organizational emotional response and organizational action The positive impact of convergence. In addition, some scholars believe that relationships can help some companies obtain valuable resources and information, thereby promoting the sustainable development of companies. At the same time, the internal network of the enterprise is also conducive to the improvisation of employees.

\subsection{Resource related factors}

Improvisation depends on the resources at hand, and the implementation of creative ideas requires sufficient resource support. Therefore, the availability of resources is conducive to the use of individual improvisation capabilities (Haidong Li and Zhiyang Lin,2013) [17]. In addition, organizational memory is a knowledge resource, which can provide rich experience and materials to help the organization quickly adapt to changes in the current situation, and the higher the level of organizational memory, the greater the possibility of improvisation. Some scholars questioned this. Studies have shown that long-term use of organizational memory for immediate use can easily lead to organizational rigidity and machinery, which is not conducive to organizational improvisation.

\subsection{Environmental atmosphere related Factors}

In order to ensure the survival and development of enterprises, organizations need to construct new behaviors immediately to face the changed environment. As far as the internal environment of the organization is concerned, when the organization advocates an error management atmosphere that tolerates errors and learns from experience in time, it is conducive to individuals seeking and obtaining valuable information and higher creativity, thereby increasing the probability of improvisation in the organization. In addition, the higher the level of team behavior integration and the greater the cohesion of the team, the higher the degree of improvisation shown by individual members (Leybourne and Sadler ,2006) [8].

\section{Integration framework construction and future prospects}

\subsection{Integration framework construction}

On the basis of combing the existing literature, this study constructed an integrated framework model (refer with: Fig.1) 


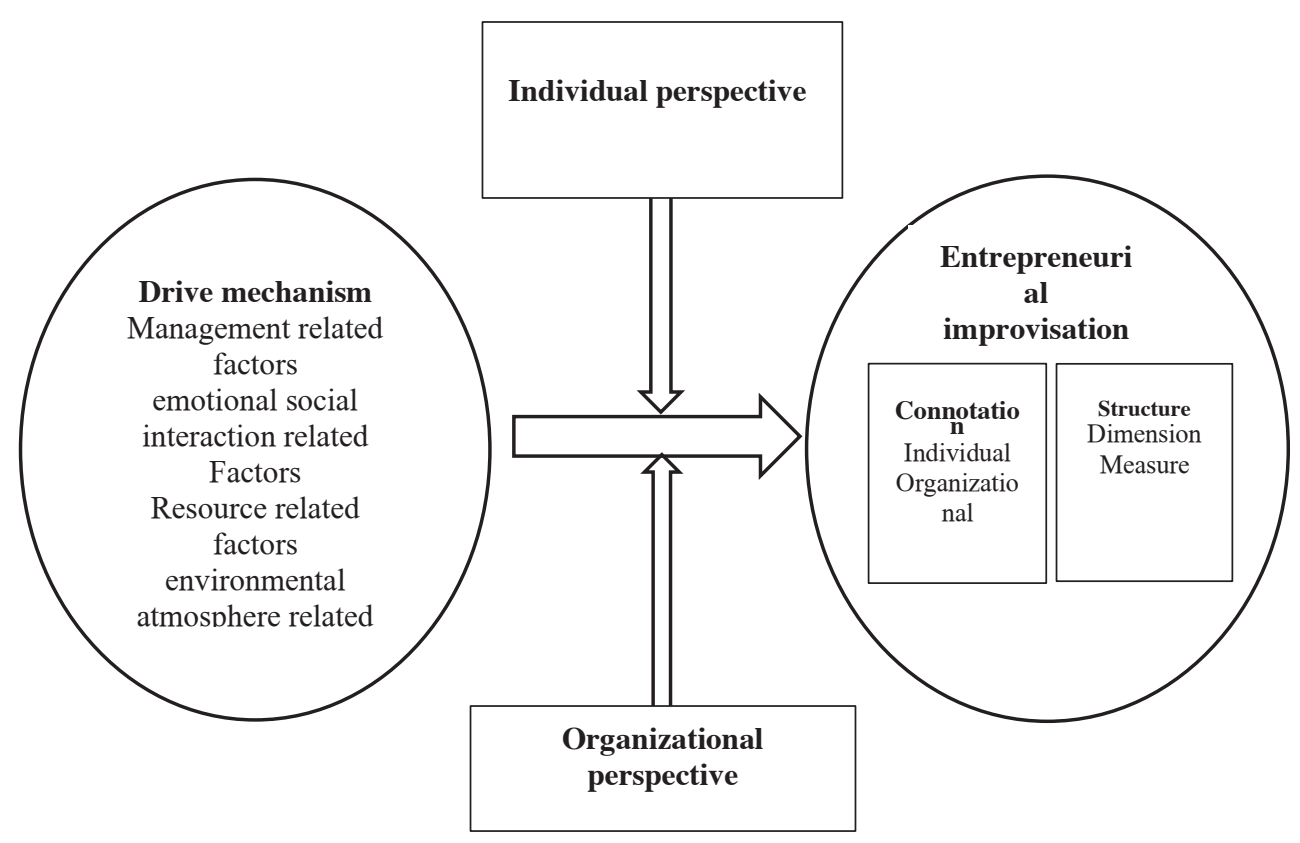

Fig. 1. Integrated research framework.

\subsection{Future research outlook}

The changing and unpredictable nature of today's business environment has made improvisation an increasingly common phenomenon in the entrepreneurial field. Although the research on entrepreneurial improvisation has made great progress, it is still in the stage of continuous exploration. Future research needs to further deepen the following aspects: First, improve the conceptual connotation of entrepreneurial improvisation and standardize the field of research. The connotation of the concept of improvisation is not the same, so many scholars have to distinguish it from other confusing concepts, which is not conducive to the research process of entrepreneurial improvisation. Under the current contextualization of entrepreneurship, an accurate definition of entrepreneurial impromptu is urgently needed, so as to explore the components of improvisation in depth and provide clear guidance for further specific research. Second, promote the output of empirical research. Pay attention to the inducing mechani21e Chinese context in order to explore the inherent characteristics of entrepreneurial improvisation.

\section{References}

1. D. Arshad, N. Zakaria, K. Abdul-Kadir, N. Ahmad, Linkage between Flexibility and SMEs Performance: Does Improvisation Matter? In MATEC Web of Conferences, 215(2018)

2. K.E. Weick, The Collapse of Sense making in Organizations: The Mann Gulch Disaster. Administrative Science Quarterly,38(4),628-652, (1993) 
3. G X Ruan, J Q Mao, L J Ma, A Cross-Level Research on the Mechanism of Employee Impromptu Behavior on Individual Innovation Performance- - Based on the Empirical Study of New Energy Startups, China Soft Science, (1),108-117, (2015)

4. Y Wang, T Y Su. A Study on the Impact Mechanism of Entrepreneurial Leadership on Employee Impromptu.Soft Science,33(11),69-74, (2019)

5. C.Moorman, A.S. Miner, Organizational Improvisation and Organizational Memory, Academy of Management Review,23(4),698-723, (1998)

6. D.Vera, M. Crossan, Improvisation and innovative performance in teams, Organization Science,16(3),203-224(2005)

7. M. P. Cunha, J V Cunha, K Kamoche, Organizational Improvisation: What, When, How, and Why,International Journal of Management Review, 1(3),299-341,(1991)

8. S Leybourne, E Sadler-Smith. The Role of Intuition and Improvisation in Project Management, International Journal of Pro- ject Management, 24(6), 483-492, (2006)

9. Z X Ye, Y Y Mai, L Y Wang. The Status Quo and Future Prospects of Research on Impromptu Behavior of Startups, Foreign Economics and Management ,40(4),16-29, (2018)

10. M Croaan, M Sorrenti, Making sense of improvisation.Advances in Strategic Management,14(3),155-180,(1997)

11. A S Miner, $P$ Bassoff, $C$ Moorman, Organizational improvisation and learning: A field study, Administrative Science Quarterly, 46(2),304 - 337, (2001)

12. K.M. Hmieleski, A. C. Corbett. Proclivity for Improvisation as a Predictor of Entrepreneurial Intentions, Journal of Small Business Management ,44(1), 45-63, (2010)

13. J Yun, C Jiang, A Review of Research on Foreign Organizational Improvisation, Foreign Social Sciences, (5),4-12, (2010)

14. L Ding, G M Cao. The Dimensional Construction and Measurement of Organizational Impromptu--Based on the Empirical Research of Chinese Commercial Banks, East China Economic Management ,000(009),84-89, (2014)

15. K. M. Hmieleski, A C. Corbett. The contrasting interaction effects of improvisational behavior with entrepreneurial self-efficacy on new venture performance and entrepreneur work satisfaction. Journal of Business Venturing, 23(4),482-496, (2008)

16. M. Magni, L. Proserpio, M. Hoegl, B. Provera. The role of team behavioral integration and cohesion in shaping individual improvisation, Research Policy, 38(6), 1044-1053, (2009)

17. H D Li, Z Y Lin. Study on the Antecedent Variables of Employees' Impromptu Behavior, Journal of Jiangxi University of Finance and Economics, (03),25-36, (2013) 